\title{
Designing Efficient Subsidy Policies in a Regional Economy: A Multicriteria Decision-Making (MCDM)-Computable General Equilibrium (CGE) Approach
}

\author{
FRANCISCO J. ANDRÉ and M. ALEJANDRO CARDENETE \\ Department of Economics, Universidad Pablo de Olavide, Ctra. Utrera, Km. 1, E-41013 Seville, Spain. \\ Emails: fjandgar@upo.es and macardenete@upo.es
}

(Received July 2006: in revised form November 2007)

André F. J. and CARdenete M. A. Designing efficient subsidy policies in a regional economy: a multicriteria decision-making (MCDM)-computable general equilibrium (CGE) approach, Regional Studies. Since policy-makers usually pursue several conflicting objectives, policy-making can be understood as a multicriteria decision problem. Following the methodological proposal by ANDRÉ and CARdenete (2005), multi-objective programming is used in connection with a computable general equilibrium model to represent optimal policy-making and to obtain so-called efficient policies in an application to a regional economy (Andalusia, Spain). This approach is applied to the design of subsidy policies under two different scenarios. In the first scenario, it is assumed that the government is concerned just about two objectives: ensuring the profitability of a key strategic sector and increasing overall output. Finally, the scope of the exercise is enlarged by solving a problem with seven policy objectives, including both general and sectorial objectives. It is concluded that the observed policy could have been Pareto-improved in several directions.

Multi-objective programming Computable general equilibrium model Efficient policy Subsidies

ANDrÉ F. J. and CARDEnEte M. A. 设计有效的区域经济补贴政策: MCDM-CGE方法, Regional Studies. 由于政策的制 定者们通常要追求多个相冲突的目标，政策制定可以理解为一个多标准决策问题。根据 ANDRÉ and CARDENETE (2005) 的方法提议, 本研究利用与可计算一般均衡模型相连接的多目标规划来描述在一个区域经济（安达鲁西亚, 西班牙）的应用中的最佳政策制定和取得所谓的有效政策。这一方法被应用于两种不同方案的补贴政策设计。在 第一个方案中，假设政府只关心两个目的：确保一个主要的战略性部门的收益和增加总的产量。最后，通过解 决一个涉及包括总的和部门的共七个政策目标的问题将练习的范围扩大。结果表明所观察到的政策在几个方面都 可进行帕累托改进。

\section{多目标规划，可计算一般均衡模型，有效政策，补贴}

André F. J. et CARdenete M. A. Mettre au point des politiques rationnelles en faveur des subventions dans le cadre d'une économie régionale: une façon MCDM-CGE, Regional Studies. Vu que normalement les décideurs poursuivent plusieurs objectifs contradictoires, on pourrait considérer la prise de décisions comme un problème à critères multiples. Conformément à l'approche proposée par Anré et Cardenete (2005), on emploie une programmation à objectifs multiples conjointement avec un modèle d'équilibre général sur ordinateur afin de représenter la prise de décisons optimales et pour engendrer des soi-disant politiques rationnelles en l'appliquant à une économie régionale (à savoir l'Andalousie, en Espagne). On applique cette approche à la mise au point des politiques en faveur des subventions dans deux cadres différents. En premier, on laisse supposer que le gouvernement ne s'occupe que de deux objectifs: assurer la rentabilité d'un secteur de pointe et augmenter le rendement global. En deuxième, on élargit la portée de l'étude en résolvant un problème à sept objectifs, y compris des objectifs généraux et sectoriels. On conclut que l'on aurait pu améliorer la politique observée dans divers domaines compte tenu de Pareto.

Programmation à objectifs multiples Modèle d'équilibre général sur ordinateur Politique rationnelle Subventions

André F. J. und Cardenete M. A. Gestaltung effizienter Subventionspolitiken in einer Regionalwirtschaft. Ein MCDM-CGEAnsatz, Regional Studies. Da Politiker in der Regel mehrere, einander widersprechende Ziele verfolgen, lässt sich Politik als multikriterielles Entscheidungsproblem auffassen. Unter Befolgung des methodologischen Vorschlags von ANDRÉ und CARDENETE (2005) setzen wir eine multikriterielle Programmierung in Verbindung mit einem berechenbaren allgemeinen Gleichgewichtsmodell in einer Anwendung für eine Regionalwirtschaft (Andalusien, Spanien) ein, um optimale Politik darzustellen und sogenannte effiziente Politiken zu erhalten. Diesen Ansatz wenden wir in zwei verschiedenen Szenarien auf die Gestaltung von 
Subventionspolitiken an. Im ersten Szenario gehen wir davon aus, dass die Regierung nur zwei Ziele verfolgt: die Sicherstellung der Rentabilität eines zentralen strategischen Sektors sowie die Erhöhung der allgemeinen Leistung. Anschließend erweitern wir den Rahmen dieser Übung, indem wir ein Problem mit sieben politischen Zielen lösen, zu denen sowohl allgemeine als auch sektorale Ziele gehören. Wir ziehen den Schluss, dass die beobachtete Politik in mehreren Richtungen einer Pareto-Verbesserung hätte unterzogen werden können.

André F. J. y CARdenete M. A. Diseño de políticas eficaces de subsidio en una economía regional. Un enfoque MCDM-CGE, Regional Studies. Dado que los responsables políticos suelen buscar en general diferentes objetivos conflictivos, la elaboración de políticas puede entenderse como un problema de decisiones con muchos criterios. Siguiendo las propuestas metodológicas de ANDRÉ y CARDENETE (2005), usamos una programación con muchos objetivos con relación a un modelo computable de equilibrio general para representar la elaboración óptima de políticas y obtener las llamadas políticas eficaces en una aplicación de economía regional (Andalucía, España). Aplicamos este planteamiento al diseño de las políticas de subsidios en dos casos diferentes. En el primer caso, suponemos que al gobierno le preocupan sólo dos objetivos: asegurar la rentabilidad de un sector estratégico clave y aumentar la productividad general. Luego aumentamos el alcance del ejercicio resolviendo un problema con siete objetivos políticos, incluyendo los objetivos generales y sectoriales. Concluimos que la política observada podría haber sido mejorada en el diagrama de Pareto en varias direcciones.

Programación con muchos objetivos Modelo de equilibrio general computable Política eficaz Subsidios

\section{INTRODUCTION}

The design of macroeconomic policies is an important issue in economics presenting important theoretical and applied challenges (for example, HolBrook, 1972; and CHOw, 1973; or, more recently, FAIR and Howrey, 1996). The traditional way to model the design of an optimal economic policy involves assuming that a social planner aims at minimizing some social loss function or maximizing some social welfare function, typically identified with the utility function of a representative consumer (for a pioneering work, see RAMSEY, 1927). This approach provides a theoretically elegant tool that links the original economic problem to the operational field of optimization theory. Nevertheless, this classical approach also presents some shortcomings concerning its realism and implement ability in practice.

To apply this classical approach, a suitable welfare function representing the preferences of society is needed. This requirement is an important difficulty from an operational point of view. Intuitive reasoning states that such a function can be very hard to find, and one's intuition is reinforced by the Social Choice line of research pioneered by ARROw (1963), showing that in standard contexts it is virtually not possible to combine the preferences of all members of the society in a single social preference relationship, with reasonable properties. On the other hand, direct observation of the usual practice in policymaking does not seem consistent with the optimization of a single specific function. Rather, policy-makers appear to be concerned about a bundle of macroeconomic indicators such as growth rate, inflation rate, unemployment rate, public deficit or foreign deficit, and they aim at improving the performance of the economy as measured by these indicators. In other words, the government typically faces a decision problem with several goals or objectives. Moreover, these objectives usually conflict with each other. For example, an active anti-unemployment policy could foster inflation; increasing economic growth could be harmful for the foreign sector, and so on.

Multicriteria decision-making (MCDM) techniques are specifically aimed at dealing with these kinds of situations in which there are multiple conflicting goals. Several particular techniques, such as multiobjective programming, compromise programming, goal programming and others, have been fruitfully applied to many economic problems in which it is not reasonable or operational to assume the existence of a single goal or objective. For an introduction to multicriteria techniques and their applications to economic problems, see BALLESTERO and ROMERO (1998); or for a state-of-the-art review, see FIGUEIRA et al. (2004). ANDrÉ and CARdenete (2005) and ANDrÉ et al. (2008) proposed to use MCDM analysis connected to a computable general equilibrium (CGE) model to address the design of macroeconomic policies. The arguments for such an approach are twofold. Firstly, from a conceptual perspective, it seems a sensible way to understand and represent the concerns and the practices actually followed by policy-makers. Secondly, from an empirical perspective, MCDM techniques, if properly applied, can be of considerable help to get operative policy recommendations and, therefore, to decide how to use policy instruments in practice.

This paper has the following goals: first, following André and CARdenete (2005) and André et al. (2008), it addresses the problem of designing economic policies in a regional economy (Andalusia, Spain) from 
a multicriteria point of view. By doing so, it somehow departs from the traditional, more theoretical approach in which the policy-maker is assumed to maximize social welfare. Instead, a more pragmatic and operational approach is used by assuming that the policy-maker has a number of policy objectives and policy-making is focused on optimizing these objectives, which seems more in line with reality. Moreover, it is shown that the approach can be seen as a generalization of the usual welfare maximizing approach. Second, this approach is applied to the design of so-called efficient subsidy policies in a regional economy. More specifically, the paper focuses on the design of efficient subsidy policies under two different scenarios. In a first exercise, it is assumed that policy-makers take into account only two objectives: output variation and the profitability of a key strategic sector such as agriculture. In a second exercise, the scope of the mentioned approach is extended by addressing policy problems with more than two objec-

$40 \mathbf{Q 1}$ tives (ANDrÉ and CARDENETE, 2005; and ANDrÉ et al., 2008, stick to bicriteria problems). Finally, the paper aims at testing if the observed subsidy policy in Andalusia is efficient or, on the contrary, it could be Pareto-improved in some direction.

The second section identifies the main elements required to represent policy-making as a multicriteria problem in a general equilibrium setting and the concept of efficient policies is defined. The third section presents the economic model used for the application and the database used to calibrate the model. The fourth section introduces some basic information about the application, including some basic description about the regional framework and the selection of policy instruments. The fifth section presents the results of two different problems. In the first case it is assumed that the regional policy-makers are concerned just about two objectives. The second case deals with the problem of designing subsidy policies when the government cares about more criteria. The sixth section summarizes the main findings of the paper and suggests some future lines of research.

\section{GENERAL SETTING: EQUILIBRIUM AND MULTICRITERIA POLICY DESIGN}

Assume there are $m$ economic agents (typically, consumers and firms), indexed by $h=1, \ldots, m$, who are assumed to act rationally in the sense that they choose the values for their decision variables (denoted as a vector $\mathbf{z}_{\mathbf{h}}$ ) to maximize their objective function $f_{\mathbf{h}}$. Typically, consumers make consumption and saving decisions to maximize utility and firms decide their factor demand and goods supply to maximize profits. Assume also the government has a vector $\mathbf{x}$ of policy instruments, which may include taxes, public expenditure and investment, interest rates, and so on.
The decision problem of agent $h$ can be represented as choosing $\mathbf{z}_{\mathbf{h}}$ to:

$$
\operatorname{Max} f_{h}\left(\mathbf{z}_{\mathbf{h}}, \mathbf{x}\right) \quad \text { subject to: } \mathbf{z}_{\mathbf{h}} \in \mathbf{R}_{\mathbf{h}}\left(\mathbf{p}, \mathbf{z}_{-\mathbf{h}}, \mathbf{x}\right)
$$

where $\mathbf{R}_{\mathbf{h}}$ is the feasible set of agent $h ; \mathbf{z}_{-\mathbf{h}}$ is the decisions of the rest of agents (different from $h$ ); $\mathbf{p}$ is a vector of prices; and $\mathbf{x}$ is the policy variables.

Let $\mathbf{Z}_{\mathbf{h}}{ }^{*}\left(\mathbf{p}, \mathbf{Z}_{-\mathrm{h}}, \mathbf{x}\right)$ denote the optimal response of agent $h$, i.e., the values of his decision variables which maximize $f_{h}$, given $\mathbf{z}_{-\mathbf{h}}, \mathbf{p}$ and $\mathbf{x}$. The interaction among agents provides the equilibrium value for prices, $\mathbf{p}^{\mathbf{e}}$, and the decision variables of all the agents, $\mathbf{Z}^{\mathbf{e}}(\mathbf{x}) \equiv\left(\mathbf{Z}_{1}^{\mathbf{e}}(\mathbf{x}), \ldots \mathbf{z}_{\mathbf{m}}^{\mathbf{e}}(\mathbf{x})\right)$, in such a way that, given the value of the policy variables, all the agents are making optimal decisions and markets clear.

Aggregating $\mathbf{z}^{\mathbf{e}}$, the value of the relevant macroeconomic variables in equilibrium is obtained (for example, gross domestic product results from the aggregation of outputs from all the firms, the consumer price index results from the weighted average of the prices of goods and services, and so on). Assume the government is interested on $K$ macroeconomic aggregates denoted as $Z_{1}, \ldots, Z_{k}$, which can be obtained from $\mathbf{z}^{\mathbf{e}}$ according to some aggregation rules:

$$
Z_{1} \equiv Z_{1}\left(\mathbf{z}^{\mathbf{e}}(\mathbf{x})\right), \ldots, Z_{K} \equiv Z_{K}\left(\mathbf{z}^{\mathbf{e}}(\mathbf{x})\right)
$$

If a policy-maker knows the response functions $\mathbf{Z}_{\mathbf{h}}{ }^{*}\left(\mathbf{p}, \mathbf{Z}_{-\mathrm{h}}, \mathbf{x}\right)$ of all the agents and the aggregation rules in (2), he can obtain the values of the policy objectives as a function of $\mathbf{x}$. If there was a single policy objective $Z(K=1)$, the optimal design of the economic policy would result from optimizing $Z$ subject to (1) and (2). In practice, there are typically several policy objectives presenting some trade-off between them. Therefore, policy-makers actually face a multicriteria problem. Following ANDrÉ and CARdenete (2005), the present paper proposes to use multi-objective programming, which is a multicriteria technique aimed at determining the set of efficient solutions. For some recent developments and applications of this technique, see Caballero et al. (2007), Doerner et al. (2007), GABRIEL et al. (2006) or Hung et al. (2006). In the present context, the multi-objective design of policies can be represented by the following problem:

$$
\begin{aligned}
& \text { Eff } \quad \mathbf{Z} \equiv\left[Z_{1}, \ldots, Z_{K}\right] \\
& \text { subject to:(1), (2), } \mathbf{x} \in \mathbf{X}
\end{aligned}
$$

where Eff is the search for efficient policies; and $\mathbf{X}$ is the feasible set for the policy instruments. A feasible policy (i.e., a value of $\mathbf{x} \in \mathbf{X}$ ) is said to be efficient if it provides some values of the objective variables $\mathbf{Z}$ such that there is no feasible policy that achieves the same of better performance for all the policy objectives being strictly 
better for at least one policy objective. Note that this concept of efficiency departs from another usual concept of efficient solution in economics, as that situation in which the total surplus of economic agents is maximized. Here a more operational concept is used from the point of view of the policy-maker based on those variables which are considered as policy objectives. On the other hand, if $f_{h}$ is defined to denote the surplus of agent $h$ and total surplus is given by $\sum_{h=1}^{m} f_{h}$, the traditional problem of maximizing total surplus can be seen as a particular case of (3) with $K=1$ and $\mathrm{Z}=\sum_{h=1}^{m} f_{h}$.

To make this approach operational, some model to represent the economy under study was also needed, i.e. some specific contents for the decision variables $\mathbf{z}_{\mathbf{h}}$, the objective functions $f_{h}$ and the interactions among economic agents. That part of the study is developed in the next section.

\section{MODEL AND DATA}

The multicriteria conception of policy-making displayed above could, in principle, be compatible with any economic model representing the decisions of economic agents and the interactions among them under different policy scenarios. The specific model should be selected by the researcher or the policymaker according to the goals of the analysis. This paper combines the multicriteria approach presented above with a CGE model.

\section{The economic model}

A CGE model is used following the basic principles of the Walrasian equilibrium - as given by SCARF and Shoven (1984) or Shoven and Whalley (1992). These kinds of models have been widely used for policy analysis. For some recent applications, see Hagger et al. (2003), NAastepad (2003), SAVArd (2005), and YAO and LIU (2000); for the state of the art, see KEHOE et al. (2005).

Following the CGE tradition, this model performs a structural disaggregated representation of the activity sectors in the economy and the equilibrium of markets according to basic microeconomic principles. Taxes and the activity of the public sector are taken as exogenous by consumers and firms, while they are considered as decision variables by the government. Assuming that consumers maximize their utility and firms maximize their profits (net of taxes), then the model provides an equilibrium solution; that is, a price vector for all goods and inputs, a vector of activity levels and a value for public income. In equilibrium, supply equals demand in all the markets ('markets clearance') and public income equals the total payments from all economic agents. To save some space, some basic features of the model are only presented. For a more detailed description of the model, see CARDENETE and SANCHO (2003b) or ANDRÉ et al. (2005).

The model comprises 25 productive sectors in order to match the social accounting matrix (SAM) (for a list of the sectors, see Table 1). Since a focus is made on aggregate results, the exact number of sectors considered is not crucial. In general, the level of disaggregation is an arbitrary decision of the researcher or the policy-maker.

There is one representative firm in each sector, a single representative consumer, one public sector and one foreign sector (which, in this application, represents the commercial relationships between Andalusia and the rest of world, including the rest of Spain and any other countries). The production technology is described by a nested production function: the domestic output of sector $j$, measured in euros and denoted by $X d_{j}$, is obtained by combining, through a Leontief technology, outputs from the rest of sectors and the value added $V A_{j}$. This value added is generated from primary inputs (labour, $L$; and capital, $K$ ), combined by a Cobb-Douglas technology. Overall output of sector $j, Q_{j}$, is obtained from a Cobb-Douglas combination of domestic output and imports Xrow , according $^{2}$ to the Armington (1969) hypothesis, in which domestic and imported products are taken as imperfect substitutes.

There are 25 different goods - corresponding to productive sectors - and a representative consumer who demands present consumption goods and saves the remainder of his disposable income after paying taxes. The government raises taxes to obtain public revenue, $R$, as well as it gives transfers to the private sector, TPS, and demands goods and services $G D_{j}$ from each sector $j=1, \ldots, 25 . P D$ is the final balance (surplus or deficit) of the public budget (in

Table 1. Productive sectors in the social accounting matrix (SAM)

\begin{tabular}{ll}
\hline 1. Agriculture & 14. Vehicles \\
2. Cattle and forestry & 15. Transport \\
3. Fishing & 16. Food \\
4. Extractives & $\begin{array}{l}\text { 17. Manufacturing of textiles } \\
\text { and leather }\end{array}$ \\
5. Refine & 18. Manufacturing of wood \\
6. Electricity & 19. Other manufactures \\
7. Gas & 20. Construction \\
8. Water & 21. Commerce \\
9. Mining & 22. Transport and communications \\
10. Manufacturing of & 23. Other services \\
construction material & \\
11. Chemicals & 24. Sales services \\
12. Manufacturing of & 25. Non-sales services \\
metal products & \\
13. Machinery &
\end{tabular}


nominal terms):

$$
P D=R-T P S \cdot c p i-\sum_{j=1}^{25} G D_{j} \cdot p_{j}
$$

where cpi is the consumer price index; and $p_{j}$ is a production price index before value added tax (VAT) referring to all goods produced by sector $j$. The consumer price index is calculated as a weighted average of the prices of all sectors, according to the participation of each one in the overall consumption of the economy.

Consumer disposable income $(Y D)$ equals labour and capital income, plus transfers, minus direct taxes:

$$
\begin{aligned}
Y D= & w \cdot L+r \cdot K+c p i \cdot T P S+T R O W \\
& -D T(r \cdot K+c p i \cdot T P S+T R O W) \\
& -D T(w \cdot L-W C \cdot w \cdot L)-W C \cdot w \cdot L
\end{aligned}
$$

where $w$ and $r$ are input (labour and capital) prices; and $L$ and $K$ are input quantities (labour and capital) sold by the consumer; TROW is transfers received by the consumer from the rest of the world; $D T$ is the tax rate of the income tax; and $W C$ is the tax rate corresponding to the payment of the employees to social security (ESS). The consumer's objective is to maximize his utility (welfare), subject to his budget constraint. Welfare is obtained from consumption goods $C D_{j}(j=1, \ldots$, $25)$ and savings $S D$, according to a Cobb-Douglas utility function, that gives rise to the following optimization problem:

$$
\max U\left(C D_{1}, \ldots, C D_{25}, S D\right)=\left(\prod_{j=1}^{25} C D_{j}^{\alpha_{j}}\right) S D^{\beta}
$$$$
\text { subject to } \quad \sum_{\mathrm{j}=1}^{25} p_{j} C D_{j}+p_{i n v} S D=Y D
$$

where $p_{\text {inv }}$ is an investment price index. Savings, SD, can be defined as the amount of income which is not consumed.

Regarding investment and saving, this is a saving driven model. The closure rule is defined in such a way that investment is exogenous, savings are determined from the consumer's decision, and both variables are related with the public and foreign sectors by the following identity:

$$
\sum_{j=1}^{25} I N V_{j} \cdot p_{i n v}=S D \cdot p_{i n v}+P D+R O W D
$$

where $I N V_{j}$ is investment in sector $j$; and ROWD is the balance of the foreign sector.
Labour and capital demands are computed under the assumption that firms minimize the cost of producing value added. Since a short-term analysis is made, in the capital market it is considered that supply is perfectly inelastic. For labour supply, the following approach is used that shows a feedback between the real wage and the unemployment rate, related to the power of unions or other factors inducing frictions in the labour market:

$$
\frac{w}{c p i}=\left(\frac{1-u}{1-u_{0}}\right)^{\frac{1}{\beta}}
$$

where $u$ and $u_{0}$ are the unemployment rates in the simulation and in the benchmark equilibrium, respectively; $w /$ cp $i$ is the real wage; and $\beta$ is a flexibility parameter. This formulation is consistent with an institutional setting where the employers decide the amount of labour demanded and workers decide real wage taking into account the unemployment rate (KEHOE et al., 1995): if labour demand increases (decreases), the unemployment rate $u$ decreases (increases) and workers demand higher (lower) real wages. If, after the simulation, employment remains unchanged, the real wage is the same as in the benchmark equilibrium. For the empirical exercises, an estimated value for Spain is taken from the econometric literature: $\beta=1.25$ (ANDRÉs et al. 1990).

Realgross domestic product (GDP) is calculated from the expenditure point of view by aggregating the values of private consumption, investment, public expenditure and net exports using constant prices.

\section{Databases and Calibration}

The main data used in this paper are those contained in the SAM of Andalusia 1995 (for the technical details about the construction of this matrix, see CARDENETE and SANCHO, 2003a), that is, the more recent one which is officially available. The SAM comprises 40 accounts, including 25 productive sectors, as shown in Table 1, two inputs (labour and capital), a saving/investment account, a government account, direct taxes (income tax and ESS) and indirect taxes (VAT, payroll tax, output tax and tariffs), a foreign sector and a representative consumer.

The numerical values for the parameters in the model are obtained by calibration (for example, MAnsur and Whalley, 1984). Specifically, the following parameters are calibrated: all the technical coefficients of the production functions, all the tax rates and the coefficients of the utility function. The calibration criterion is that of reproducing the 1995 SAM as an initial equilibrium for the economy, which is used as a benchmark for all the simulations. In such an equilibrium, all the prices and activity levels are set equal to 1 and, therefore, after the simulation it is 
possible to observe directly the change rate of relative prices and activity levels. When finding the economic equilibrium corresponding to the policy combinations in the optimization exercises, the interest rate is taken as numeraire and the rest of the prices are allowed to vary as required to meet equilibrium conditions.

\section{APPLICATION: DESIGNING AN EFFICIENT SUBSIDY POLICY IN ANDALUSIA}

Regional framework: Andalusia

Andalusia, which is a large region in the south of Spain, has been designated by the European Union as an Objective 1 region (for more information, see LiMA and Cardenete, 2007). Moreover, it is also the Spanish region that has traditionally received the largest amount of public subsidies because of its economic situation, geographical extension and population.

570 The causes of inequality in this economy can be explained by the important lack of infrastructures, necessary to develop the economic activity, and the need of a better qualification of human capital in all educational levels. Andalusia has received an important financial support from Europe since the European Union approved the first Community Support Framework (CSF). In this document, the European Commission signed an agreement with national governments to determine the European financial grants for the period 1989-93. The same trend has occurred for the periods 1994-99, 2000-06 and also at the beginning of CSF 2007-13. In Spain, all the funds received from Europe have been managed by the Central Government and the Regional Governments. Actually, the Regional Governments have a high degree of freedom to allocate the subsidy funds across sectors in order to impulse different economic activities.

In the case of Andalusia, a large number of sectors receive a net subsidy on production. According to the SAM of Andalusia 1995, all the activity sectors listed in Table 1 received a positive net subsidy on production (defined as the difference between subsidies and output taxes) except sectors 3 (Fishing), 5 (Refine), 10 (Manufacturing of Construction Material), 21 (Commerce), 23 (Other Services) and 25 (Non Sales Services).

\section{Setting the policy-making problem: policy instruments and policy objectives}

600 For the policy-making problem to be fully described, one needs to select, first, the policy instruments and, second, the policy objectives.

Concerning policy instruments, focus is made on the design of an efficient subsidy policy at the regional level. Therefore, the net subsidy rates of those sectors that received a net subsidy in the benchmark situation are selected as policy variables. The subsidy rate is defined as the ratio of the net subsidy (total subsidy minus taxes on production) over the value of domestic output in the sector, i.e., the net subsidy per unit of domestic output.

In order to avoid obtaining policy recommendations unrealistically far away from real applied policies, the following constraints on the policy instruments were assumed:

- The sectors that are not subsidized, in net terms, in the benchmark situation (the observed values in Andalusia, 1995) are assumed to remain being nonsubsidized.

- For the sectors that are subsidized in the benchmark situation, two feasible bounds for the new (simulated) subsidy rate are set: the lower bound is zero (meaning that the subsidy is fully eliminated) and the upper bound is the observed value times 1.5 (meaning that the subsidy rate is increased in a 50\%).

- The rest of policy instruments (VAT, income tax, public expenditure, etc.) are assume to have the same value as in the benchmark situation.

For the problem to be fully described, it is necessary to specify the relevant policy objectives. The next section presents, first, a problem with two objectives and, second, a problem with more than two policy objectives.

\section{RESULTS}

A bicriteria problem: output variations versus agricultural profit

As discussed in the previous section, due to different reasons, the economic policy in Andalusia is, to a large extent, based on subsidies. The agricultural sector is one of the key activity sectors in the Andalusia, and one of sectors that have been traditionally subsidized. Since the beginning of the 1980s, this sector has received an important amount of funds from the European Community in an attempt to modernize and develop this activity.

Based on this observation, the section starts by setting a problem in which the regional government is assumed to design its subsidy policy according to two objectives. The first objective is to foster the overall activity of the economy in real terms. This objective is represented as the maximization of output variation, denoted by $\Delta Q$, with respect to the benchmark situation. The second objective is to increase the profit of the agricultural sector in order to make this activity as profitable as possible. This objective is represented as the maximization of the firms profit in the agricultural sector (as measured by the gross exploitation surplus). For the sake of normalization, focus is made on the growth rate of profit with respect to the benchmark situation, denoted as $\Delta \pi_{\text {Agric }}$, rather than the value of profit itself in absolute terms. The rationale under the selection of these objectives is that the government might be interested in promoting a key activity sector (such as the agricultural 
one) but, on the other hand, it probably does not want to do it at the expense of damaging too much the economy as a whole.

Ideally, the government would like to design a subsidy policy such that both objectives could reach a very high score. Therefore, the first step is to assess if these objectives are mutually compatible or, on the contrary, both of them conflict with each other. The degree of compatibility or conflict between both objectives can be studied by computing the so-called payoff matrix. This is done by solving two monocriteria problems which consist of optimizing each objective separately disregarding the other one. First, the maximum value of the output variation is computed, subject to the specified constraints on the policy variables and all the equations of the model. This maximum value is referred to as the ideal value of the output variation and denoted as $\Delta Q^{*}$. By plugging the optimal values of the policy variables (in or case, net subsidies) $x_{\Delta Q}=\arg \max \Delta Q$ in the relevant equations of the model, an associated value of the firms profit variation in the agricultural sector is obtained. Both of these values are displayed in the first row of the pay-off matrix (Table 2). In the same way, the ideal value of the agricultural profit increment $\Delta \pi_{\text {Agric }}{ }^{*}$ and the associated value of the output variation are obtained. The worst $(=$ minimum) value of each column is the anti-ideal value for the associated objective: $\Delta Q^{*}$ and $\Delta \pi_{\text {Agric }}{ }^{*}$, which correspond to the achievement of each objective, when the other one is optimized.

The first row of Table 2 shows that it would be possible to implement a subsidy policy in order to obtain an output increment $\Delta Q^{*}=1.99 \%$. As a by-product of this policy, the profit of agricultural firms would experience a modest increment of $0.25 \%$. The second row shows that (as a consequence of a different subsidy policy) it would be possible to increase the agricultural

Q3 profit in 1.93\%. Nevertheless, this policy would imply that a reduction in the overall output of the economy is $0.74 \%$. The values in the main diagonal (the maximum output variation and the maximum agricultural profit increment) represent the ideal point and the vector with the worst element of each row gives the so-called anti-ideal point.

From Table 2 it can be concluded that there is some degree of conflict between both objectives in the sense that it is not possible to get at the same time the maximum output variation and maximum increment of

Table 2. Pay-off matrix output variations versus profit in agriculture

\begin{tabular}{lrc}
\hline & $\Delta Q(\%)$ & $\Delta \pi_{\text {Agric }}(\%)$ \\
\hline $\operatorname{Max} \Delta Q$ & 1.99 & 0.25 \\
$\operatorname{Max} \Delta \pi_{\text {Agric }}$ & -0.74 & 1.93 \\
\hline
\end{tabular}

Source: Authors' own elaboration. the agricultural profit. This conflict is an essential element to have a genuine multicriteria (in this case, bicriteria) problem. Since it is no possible to achieve the optimal value of both objectives simultaneously, the policy-maker must establish some compromise between them.

The second step is to determine the set of efficient policies. In this case, a policy combination $x$ providing the objective values $\left(\Delta Q, \Delta \pi_{\text {Agric }}\right)$ is said to be efficient if there is not another feasible policy, say $x^{\prime}$, providing $\left(\Delta Q^{\prime}, \Delta \pi_{\text {Agric }}{ }^{\prime}\right)$ such that either $\Delta Q^{\prime} \geq \Delta Q$ and $\Delta \pi_{\text {Agric }}{ }^{\prime}>\Delta \pi_{\text {Agric }}$, or $\Delta Q^{\prime}>\Delta Q$ and $\Delta \pi_{\text {Agric }}{ }^{\prime} \geq$ $\Delta \pi_{\text {Agric }}$. An approximation to the efficient set is obtained using the so-called constraint method, which consists of optimizing one of the objectives, while the other one is placed as a parametric constraint. In the present case, a grid is made for the feasible values of $\Delta \pi_{\text {Agric }}$, from 0.25 to 1.93 . Let $\Delta \pi_{n}$ denote one specific value of $\Delta \pi_{\text {Agric }}$ in the grid. For each of these values, the problem $\max \Delta Q$ is solved subject to the constraint $\Delta \pi_{\text {Agric }} \geq \Delta \pi_{n}$ and all the equations in the model (it is arbitrary which objective is parameterized and which one is optimized in every point).

Fig. 1 illustrates the results of these calculations with ten efficient combinations denoted as $E_{1}, \ldots, E_{10}$. The line connecting this points represents a frontier of efficient policies. The combinations below this frontier can be considered as being inefficient, whereas the combinations above it are infeasible. It can be seen that, along the efficient frontier, there is a monotonic relationship between output variation and the increment of agricultural profit, but the trade-off between both rates, as measured by the slope of the frontier, is not constant. As a matter of fact, the frontier is concave, which means that increasing agricultural profit (moving from left to right) implies an increasing cost in terms of lost overall output.

Table 3 displays the subsidy rate as a percentage of production in the original benchmark situation (shadowed column) as well as in every of the efficient points in Fig. 1. The first thing that can be noted is that, in all the points of the frontier, the subsidy of the

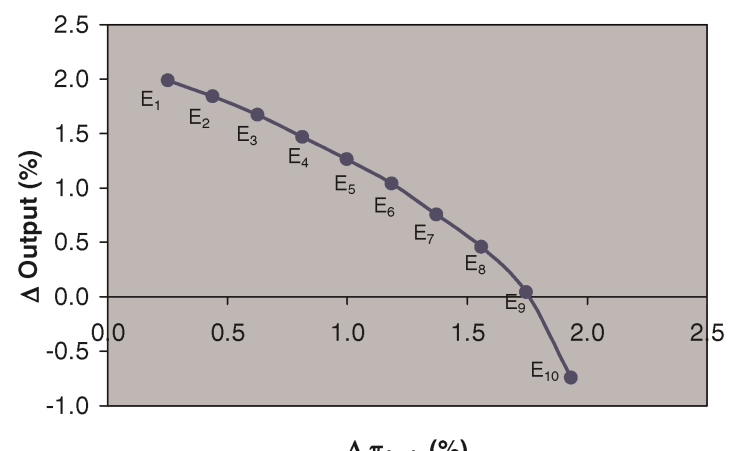

Fig. 1. Trade-off between agricultural profit and output variation 
Table 3. Net subsidy by sectors in a benchmark situation and in efficient points in the bicriteria problem

\begin{tabular}{|c|c|c|c|c|c|c|c|c|c|c|c|}
\hline \multirow[b]{2}{*}{ Sector } & \multirow[b]{2}{*}{ Bench } & \multicolumn{10}{|c|}{ Subsidy rate (\%) in efficient point, $\mathrm{E}_{\mathrm{n}}$} \\
\hline & & $\mathrm{E}_{1}$ & $\mathrm{E}_{2}$ & $\mathrm{E}_{3}$ & $\mathrm{E}_{4}$ & $\mathrm{E}_{5}$ & $\mathrm{E}_{6}$ & $\mathrm{E}_{7}$ & $\mathrm{E}_{8}$ & $\mathrm{E}_{9}$ & $\mathrm{E}_{10}$ \\
\hline 1 & 2.98 & 4.48 & 4.48 & 4.48 & 4.48 & 4.48 & 4.48 & 4.48 & 4.48 & 4.48 & 4.48 \\
\hline 2 & 3.09 & 4.64 & 4.60 & 4.64 & 4.64 & 4.64 & 4.64 & 4.64 & 4.64 & 4.64 & 4.64 \\
\hline 4 & 36.22 & 54.33 & 54.30 & 54.33 & 36.92 & 7.89 & - & - & - & - & - \\
\hline 6 & 3.04 & 1.44 & - & 4.56 & 4.56 & 4.56 & - & - & - & - & - \\
\hline 7 & 7.97 & 11.95 & 12.00 & 11.95 & 11.95 & 11.95 & - & - & - & - & - \\
\hline 8 & 2.69 & 4.04 & 4.00 & 4.04 & 4.04 & 4.04 & 4.04 & 4.04 & 4.04 & 4.04 & 4.04 \\
\hline 9 & 0.55 & 0.82 & - & - & - & - & - & - & - & - & - \\
\hline 11 & 9.51 & 14.26 & 14.30 & 14.26 & 14.26 & 14.26 & 14.26 & 14.26 & 14.26 & 14.26 & - \\
\hline 12 & 2.87 & 4.30 & 4.30 & 4.30 & 4.30 & 4.30 & 0.00 & 0.00 & 0.00 & - & - \\
\hline 13 & 19.66 & 0.00 & 2.60 & 29.49 & 29.49 & 29.49 & 29.49 & 22.84 & 0.89 & - & - \\
\hline 14 & 36.02 & 54.04 & 54.04 & 54.04 & 54.04 & 54.04 & 54.04 & 22.13 & - & - & - \\
\hline 15 & 5.67 & 8.50 & 8.50 & 6.25 & - & - & - & - & - & - & - \\
\hline 16 & 9.59 & 14.38 & 14.40 & 14.38 & 14.38 & 14.38 & 14.38 & 14.38 & 14.38 & 14.38 & 14.38 \\
\hline 17 & 16.25 & 24.38 & 24.38 & 24.38 & 24.38 & 24.38 & 24.38 & 24.38 & 24.38 & 20.51 & - \\
\hline 18 & 5.90 & 8.85 & 8.80 & 8.85 & 8.85 & 8.85 & 0.55 & - & - & - & - \\
\hline 19 & 10.06 & 15.09 & 15.09 & 15.09 & 15.09 & 15.09 & 15.09 & 15.09 & 15.09 & - & - \\
\hline 20 & 3.64 & - & - & 0.30 & 1.08 & 1.96 & 3.77 & 5.47 & 5.47 & 5.47 & 5.47 \\
\hline 22 & 5.08 & 7.61 & 3.80 & - & - & - & - & - & - & - & - \\
\hline 24 & 4.80 & - & - & - & - & - & - & - & - & - & - \\
\hline
\end{tabular}

Source: Authors' own elaboration. subsidies across the efficient points, including the Q4 number of subsidized sectors (purple bars) and the total public net expenditure in terms of subsidies (blue dotted line). It can be seen that a higher required valued for agricultural profit comes hand with hand with a reduction in the number of subsidized sectors and a smaller amount of expenditure devoted to subsidies. The interpretation of this fact is the following: if one wants to benefit the agricultural sector, and it is not possible to increase its subsidy, one possible thing to do is to increase the subsidies of those sectors that are complementary to Agriculture and eliminate the subsidies of other sectors in such a way that Agriculture has the same treatment in absolute terms but a better treatment in relative terms (as compared with the rest of sectors).

\section{A problem with more than two criteria}

In order to enlarge the scope of the discussion made so far, consider the possibility that the government is concerned about a larger number of criteria. To illustrate the way to deal with this kind of setting, assume the government has two types of objectives: general economic objectives and strategic sectorial objectives.

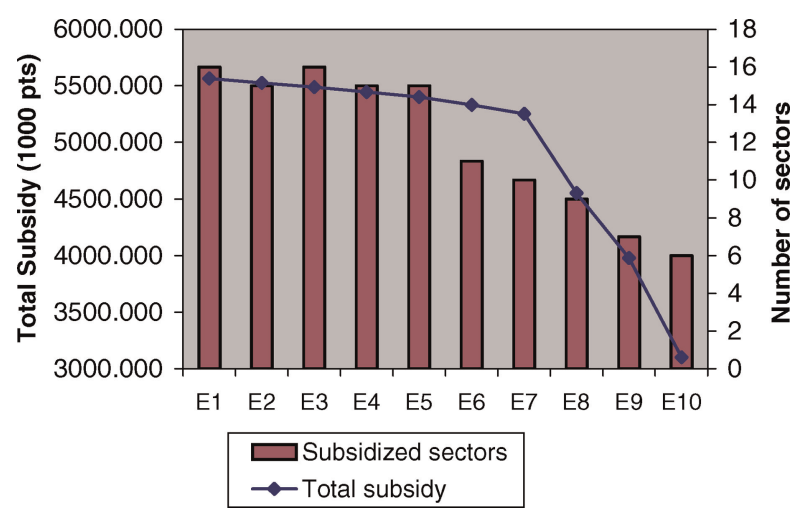

Fig. 2. Number of subsidized sectors and the total amount spent in subsidies across efficient points in the bicriteria problem 
Among the general economic objectives, it is assumed that the government is concerned, first, about the variation of output with respect to the benchmark situation (see the previous section). Since the government is also supposed to aim at increasing social welfare, included as an objective is (the maximization of) compensating variation $(\mathrm{CV})$ which is a conventional welfare measure in monetary terms (for example, MAs-Colell et al., 1995, p. 82). CV is arbitrarily set to zero in the observed situation, in such a way that $C V>0(<0)$ means that, after implementing the analysed policy combination, the consumers are better off (worse off) than before implementing it. The third objective is to minimize the public deficit, which is denoted as $-P D$ (since the balance of the public budget is always negative, both in the observed situation and in all the simulated cases). The fourth objective is to minimize the unemployment rate, $u$.

Concerning the sectorial objectives, assume the government is particularly interested in ensuring the viability of some key strategic sectors. Assume these sectors are sector 1 (Agriculture), 20 (Construction) and 22 (Transports and Communications). Therefore, the government sets as policy objectives maximizing the profit (as measured by the gross exploitation surplus) of these sectors. For the sake of normalization, focus is made on the increment of profit with respect to the benchmark situation, denoted as $\Delta \pi_{1}, \Delta \pi_{20}$ and $\Delta \pi_{22}$, respectively.

By solving seven monocriteria problems, the pay-off matrix is obtained, which is shown in Table 4. As in the previous exercises, the values in the main diagonal, which are emboldened, represent the ideal point, whereas the vector containing the worst value for each column (italicized) is the anti-ideal point. A visual inspection of the matrix allows the identification of some conflicts among objectives.

This section first focuses on general macroeconomic policy objectives. It turns out that output variation, consumer welfare (as measured by compensatory variation) and unemployment minimization have a joint behaviour in the sense that there is no conflict among them. Actually, the optimization of the two first objectives provides exactly the same solution, whereas unemployment minimization provides a very similar solution.
On the other hand, these three objectives strongly conflict with public deficit minimization, since optimizing any of these objectives results in a public deficit well above the minimum attainable level and minimizing public deficit provides very poor results for output variation, consumer welfare and unemployment minimization. It is remarkable that unemployment shows a low degree of sensitivity with respect to any macroeconomic policy, since the range of variation of $u$ is very small. This result is coherent with other existing studies for Andalusia in the literature (for example, Cardenete and Sancho, 2003b) and it amounts to the notably high values of unemployment displayed in Table 4. Recall that unemployment has traditionally been a very hard problem in Spain (for example, BLANCHARD et al., 1995) and especially in Andalusia. For example, in 1993 the unemployment rate was $23.90 \%$ in Spain and 34.18\% in Andalusia. In 2002 it was $11.36 \%$ in Spain and 19.65\% in Andalusia (data from the Andalusian Statistical Institute - IEA).

Concerning sectorial objectives, as discussed above, maximizing the profitability of the agricultural sector (sector number 1) clearly conflicts with the objective of maximizing output variation, and note that it also conflicts with the maximization of compensatory variation and, to some extent, with unemployment minimization. The profitability of the transports sector (number 22) conflicts even more clearly with output variation, consumer welfare and unemployment minimization. On the other hand, any of these general objectives displays a very clear conflict with the profitability of the construction sector (number 20). Finally, the profitability of Construction and Transports seem to conflict very clearly with each other and any of them have a moderate degree of conflict with the agricultural sector.

The paper now illustrates two alternative ways to obtain efficient policies: the previously used constraint method and the weighting method (for example, Ballestero and Romero, 1998). To apply the constraint method, a single objective needs to be optimized while keeping the rest as parametric constraints. To illustrate the use of this technique, all objectives are forced except the one being optimized to have a value

Table 4. Pay-off matrix of the problem with seven objectives

\begin{tabular}{|c|c|c|c|c|c|c|c|}
\hline & $\Delta Q$ & $C V$ & $P D$ & u & $\Delta \pi_{1}$ & $\Delta \pi_{20}$ & $\Delta \pi_{22}$ \\
\hline $\operatorname{Max} \Delta Q$ & 1.99 & 7871.61 & 108396.95 & 33 & 0.25 & 3.94 & 0.48 \\
\hline Max $C V$ & 1.99 & 7871.61 & 108396.95 & 33 & 0.25 & 3.94 & 0.48 \\
\hline Max $P D$ & -4.08 & -40127.87 & 72773.80 & 38 & 1.40 & -1.52 & 0.99 \\
\hline $\operatorname{Min} u$ & 1.98 & 7811.18 & 108360.29 & 33 & 0.26 & 3.73 & 0.47 \\
\hline $\operatorname{Max} \Delta \pi_{1}$ & -0.74 & -11709.20 & 96890.17 & 33 & 1.93 & 2.49 & -0.69 \\
\hline $\operatorname{Max} \Delta \pi_{20}$ & 1.57 & 5461.34 & 109432.74 & 37 & 0.68 & 4.80 & -1.18 \\
\hline $\operatorname{Max} \Delta \pi_{22}$ & -3.19 & -32366.48 & 79293.65 & 34 & 0.53 & -1.65 & 2.72 \\
\hline
\end{tabular}

Notes: $\Delta Q, u, \Delta \pi_{1}, \Delta \pi_{20}$ and $\Delta \pi_{22}$ are measured in percentages. CV and PD are measured in $€ 10^{6}$. Emboldened values in the main diagonal are the ideal point; italicized values are the vector containing the worst value for each column. Source: Authors' own elaboration. 
equal to or better than that in the observed situation. The observed values (taken from the databases reported in the third section) are as follows:

$$
\begin{aligned}
\Delta Q & =C V=\Delta \pi_{1}=\Delta \pi_{20}=\Delta \pi_{22}=0, \quad P D \\
& =110800.67, \quad u=33.9 \%
\end{aligned}
$$

where $P D$ and $C V$ are measured in millions of euros.

1000 Thus, the first candidate point is obtained by solving the following problem:

$$
\begin{aligned}
& \operatorname{Max} \Delta Q \quad \text { subject to: } C V \geq 0, P D \leq 110800.67 \\
& \quad u \leq 33.9, \Delta \pi_{1} \geq 0 \\
& \Delta \pi_{20} \geq 0, \Delta \pi_{22} \geq 0 \\
& \text { all the equations of the model }
\end{aligned}
$$

The solution of problem (10) is represented in the first row of Table 5. Note that this combination Pareto-dominates the observed situation (9), since not only output increases with respect to the observed one, but also the $C V$ is larger, public deficit and unemployment are lower, and the profits of all the target sector are higher than in the benchmark situation. Therefore, it is concluded that, according to the setting, the observed policy displays some degree of inefficiency and it could be unambiguously improved with respect to the seven objectives considered here.

By doing similar calculations for each objective, six more combinations are obtained, which are displayed in Table 5. Note again that the solution for the two first criteria (output variation and compensating variation) are identical. Moreover, the solutions for these criteria are exactly the same as those in Table 4 . The reason is simply that the constraints imposed when solving problem (10) are not binding since the unconstrained optima shown in Table 4 dominate the

\begin{tabular}{|c|c|c|c|c|c|c|c|}
\hline & $\Delta Q$ & $C V$ & $P D$ & $u$ & $\Delta \pi_{1}$ & $\Delta \pi_{20}$ & $\Delta \pi_{22}$ \\
\hline $\operatorname{Max} \Delta Q$ & 1.99 & 7871.61 & 108396.95 & 0.33 & 0.25 & 3.94 & 0.48 \\
\hline Max $C V$ & 1.99 & 7871.61 & 108396.95 & 0.33 & 0.25 & 3.94 & 0.48 \\
\hline Max PD & 0.75 & 655.03 & 105104.28 & 0.34 & 0.80 & 3.30 & 0.37 \\
\hline $\operatorname{Min} u$ & 1.74 & 7172.33 & 109274.53 & 0.33 & 0.27 & 4.01 & 0.58 \\
\hline $\operatorname{Max} \Delta \pi_{1}$ & 0.53 & 363.16 & 108395.84 & 0.34 & 1.38 & 3.19 & 0.00 \\
\hline $\operatorname{Max} \Delta \pi_{20}$ & 1.73 & 6594.76 & 108992.69 & 0.33 & 0.47 & 4.40 & 0.00 \\
\hline $\operatorname{Max} \Delta \pi_{22}$ & 0.40 & 461.90 & 110794.67 & 0.34 & 0.00 & 2.57 & 1.33 \\
\hline
\end{tabular}
observed situation for all the objectives. Nevertheless, the situation is different for other rows in Table 5, since the unconstrained optimal values (those in

Table 5. Using the constraint method with respect to the observed situation

Notes: $\Delta Q, u, \Delta \pi_{1}, \Delta \pi_{20}$ and $\Delta \pi_{22}$ are measured in percentages. CV and $\mathrm{PD}$ are measured in $€ 10^{6}$.

Source: Authors' own elaboration.
Table 4) do not meet the requirement that no objective achieves a worse value than in the benchmark situation. This makes the constrained optima being different from the unconstrained ones.

A sufficient condition for the constraint method to provide efficient solutions is that all the parametric constraints are binding. Since this is not the case for some constraints, one cannot ensure that all the solutions displayed in Table 5 are efficient, although any of them Pareto-dominates the observed situation. The fact that these combinations dominate the observed situation ensures that the policy actually implement is inefficient with respect to the selected objective.

In order to find solutions that can guarantee they are efficient, two possibilities are obtained: the first still uses the constraint method and makes the parametric constraints tougher by increasing the value of the "more is better objectives' $\left(\Delta Q, C V, \Delta \pi_{1}, \Delta \pi_{20}\right.$ and $\left.\Delta \pi_{22}\right)$ and/or decreasing the value of the 'less is better' objectives $(-P D$ and $u)$ until a solution is found in which all the constraint are binding at the same time.

The second approach is to use the so-called weighting method. This method consists of maximizing the following sum of normalized value of objectives:

$$
\sum_{i=1}^{7} \omega_{\gamma_{i}} \frac{\gamma_{i}-\gamma_{i} *}{\gamma_{i}^{*}-\gamma_{i} *}
$$

where $\gamma_{i}$ is the achieved value for objective $i=1, \ldots, 7$, i.e., $\gamma_{1}=\nabla \mathrm{Q}, \ldots, \gamma_{7}=\nabla \pi_{22}$, and each objective is normalized by subtracting the anti-ideal value and dividing by the difference between the ideal and the anti-ideal value (taken from Table 4). For each $\gamma_{i}$, the resulting ratio is bounded by construction between zero (when the objective is equal to the anti-ideal) and 1 (when it is equal to the ideal). This normalization eliminates units of measurement and allows the addition having mathematical and economic sense. The coefficients $\omega_{\gamma i}$ are preference parameters representing how concerned the policy-maker is about each objective $i$. The policy combination obtained is illustrated with $\omega_{\gamma 1}=\ldots=\omega_{\gamma 7}$, meaning that the policy-maker is equally concerned about the level of achievement of all the objectives. The maximization of (11) with this set of weights gives the following solution:

$\Delta Q=0.21 \%, C V=€-23.49 \times 10^{6}, P D=€ 108$ $147.12 \times 10^{6}, \mathrm{u}=33.9 \%, \Delta \pi_{1}=0.77 \%, \Delta \pi_{20}=$ $1.12 \%$, and $\Delta \pi_{22}=-1.15 \%$

which is an efficient solution by construction. Note that this procedure ensures that the solutions found are efficient (provided $\omega_{\gamma i}>0$ for all the objectives), but it does not guarantee that all the criteria improve with respect to the observed situation. Actually, the solution found for equal weights does not Pareto-dominate the observed solution in Andalusia 1995 since some policy objectives improve and other worsen with respect to the observed situation. By testing different 
combinations of weights, different efficient solutions are obtained that might respond to different preference configurations of the policy-maker.

\section{CONCLUSIONS}

This paper claims that economic policy-making can be suitably represented as a multicriteria problem for a double reason. Firstly, from a conceptual perspective, it seems a sensible way to understand and represent the concerns and the procedures actually followed by policy-makers. Secondly, from an empirical perspective, multicriteria decision-making (MCDM) techniques can be of considerable help to get operative policy recommendations and, therefore, to decide how to use policy instruments in practice.

A computable general equilibrium (CGE) model properly calibrated for the Andalusian economy allows one to analyse the subsidy policy and to identify efficient subsidy combinations once the relevant policy criteria have been identified.

Under the assumption that the policy-maker is concerned only about two policy objectives (output variation and the increment of profit in the agricultural sector), it turns out that there is a conflict between both of them. This means that it is not possible to obtain the best possible result for both objectives at the same time or, in other words, there is a trade-off between increasing agricultural profit and increasing overall output. By studying the efficient policies, the following conclusions were derived. First, increasing the subsidy of the agricultural sector is a policy change that appears to be consistent with both increasing agricultural profit and increasing overall output. Second, when the policy-maker gets more concerned about increasing agricultural profit (and is willing to accept a lower value of total output), the model recommends that one increases the subsidies of those sectors that are complementary to Agriculture and eliminate the subsidies of other sectors.

Enlarging the number of objectives makes the problem computationally more demanding but also more interesting and realistic. By including seven policy objectives, it has been shown that the observed policy could have been unambiguously improved in a number of ways depending on the weight given by the policy-maker to each objective.

This paper aims at providing a first approximation to the multicriteria analysis of policy-making in a regional economy and getting some initial insights in this framework. The analysis can be extended and improved in a number of ways. First, it would be possible to construct a model at two levels: regional and nationwide. This would allow one to consider trade-offs and conflicts between regional and national considerations. Second, the analysis has been restricted to a short-term approach. A dynamic version of the model could be used to address intertemporal issues related to policy efficiency. Finally, another line for improvement is to refine the definition and selection of policy objectives. These extensions are left for future work, since the fundamental contribution of this paper is not the model itself, but rather to suggest a methodological line of research combining different analytical instruments: a structural economic model, such as a CGE model, and a more operational tool, such as MCDM.

Acknowledgements - The authors thank Carlos Usabiaga for useful discussions. Francisco J. André thanks European Research Project EFIMAS and Project No. SEJ2005-0508/Econ from the Spanish Ministry of Education and Science. M. Alejandro Cardenete thanks Project No. SEC2003-05112 from the Spanish Ministry of Education and Science and Project No. XT0095-2004 from the Generalitat de Catalunya.

\section{REFERENCES}

André F. J. and Cardenete M. A. (2005) Multicriteria Policy Making. Defining Efficient Policies in a General Equilibrium Model. Working Paper No. E2005/04, Centro de Estudios Andaluces, Seville.

André F. J., CARdenete M. A. and Romero C. (2008) Using compromise programming for macroeconomic policy making in a general equilibrium framework: theory and application to the Spanish economy, Journal of the Operational Research Society $\mathbf{5 9}$, $875-883$.

André F. J., Cardenete M. A. and Velázquez E. (2005) Performing an environmental tax reform in a regional economy. a computable general equilibrium approach, Annals of Regional Science 39, 375-392.

Andrés J., Dolado J. J., Molinas C., Sebastián M. and Zabalza A. (1990) The influence of demand and capital constraints on Spanish unemployment, in Drèze J. and BeAn C. (Eds) Europe's Unemployment Problem, MIT Press, Cambridge, MA.

Armington P. S. (1969) A theory of demand for products distinguished by place of production. International Monetary Fund, Staff Papers 16, 159-178.

Arrow K. J. (1963) Social Choice and Individual Values, Yale University Press, New Haven, CT.

Ballestero E. and Romero C. (1998) Multiple Criteria Decision Making and its Applications to Economic Problems, Kluwer, Dordrecht.

Blanchard O. et al. (1995) Spanish Unemployment: Is There a Solution?, Centre for Economic Policy Research, London.

Caballero R., González M., Guerrero F. M., Molina J. and Paralera C. (2007) Solving a multiobjective location routing problem with a metaheuristic based on tabu search. Application to a real case in Andalusia, European Journal of Operational Research 177, 1751-1763. 
Cardenete M. A. and Sancho F. (2003a) Evaluación de multiplicadores contables en el marco de una matriz de contabilidad social regional, Investigaciones Regionales 2, 121-139.

CARdenete M. A. and SAncho F. (2003b) An applied general equilibrium model to assess the impact of national tax changes on a regional economy, Review of Urban and Regional Development Studies 15, 55-65.

Chow G. (1973) Problems of economic policy form the viewpoint of optimal control, American Economic Review 63, 825-837.

Doerner K., Focke A. and GutjAhr W. J. (2007) Multicriteria tour planning for mobile healthcare facilities in a developing country, European Journal of Operational Research 179, 1078-1096.

FAIR R. C. and Howrey E. P. (1996) Evaluating alternative monetary policy rules, Journal of Monetary Economics 38, $173-193$.

Figueira J., Greco S. and Ehrgott M. (Eds) (2004) Multiple Criteria Decision Analysis: State of the Art Surveys. International Series in Operations Research \& Management Science, Springer, Berlin.

Friedman M. (1968) The role of monetary policy, American Economic Review 58, 1-17.

Gabriel S. A., Faria J. A. and Moglen G. E. (2006) A multiobjective optimization approach to smart growth in land development, Socio-Economic Planning Sciences 40, 212-248.

Hagger A. J. and Madden J. R. with Groenewold N. (2003) Interregional transfers: a political-economy CGE approach, Papers in Regional Science 82, 535-554.

Holbrook R. S. (1972) Optimal economic policy and the problem of instrument instability, American Economic Review 62, $57-65$.

Hung M. L., YANG W., Ma H. W. and YANG Y. M. (2006) A novel multiobjective programming approach dealing with qualitative and quantitative objectives for environmental management, Ecological Economics 56, 584-593.

Kehoe T. J., Polo C. and Sancho F. (1995) An evaluation of the performance of an applied general equilibrium model of the Spanish economy, Economic Theory 6, 115-141.

Kehoe T. J., Srinivasan T. N. and Whalley J. (Eds) (2005) Applied General Equilibrium Modeling, Cambridge University Press, Cambridge.

Lima C. and Cardenete M. A. (2007) The effects of European Structural Funds in a regional economy: an applied general equilibrium analysis, Applied Economic Letters 14, 851-855.

MANSUR A. and Whalley J. (1984) Numerical specification of applied general equilibrium models: estimation, calibration, and data, in Scarf H. and Shoven J. B. (Eds) Applied General Equilibrium Analysis, pp. 69-117, Cambridge University Press. Cambridge.

Mas-Colell A., Whinston M. D. and Green J. R. (1995) Microeconomic Theory, Oxford University Press, New York, BY.

NAastepad C. W. M. (2003) Restoring macroeconomic stability through fiscal adjustment: a real-financial CGE analysis, Review of Development Economics 7, 445-461.

RAMSEY R. P. (1927) A contribution to the theory of taxation, Economic Journal 37, 47-61.

SAVARD L. (2005) Poverty and inequality analysis within a CGE framework: a comparative analysis of the representative agent and microsimulation approaches, Development Policy Review 23, 313-331.

Scarf H. and Shoven J. B. (Eds) (1984) Applied General Equilibrium Analysis, Cambridge University Press. Cambridge.

Shoven J. B. and Whalley J. (1992) Applying General Equilibrium, Cambridge University Press, New York, NY.

YAO S. and LiU A. (2000) Policy analysis in a general equilibrium framework, Journal of Policy Modeling 22, 589-610. 